\title{
An AR Memory App based on Māori Mnemonic Aids
}

\author{
Ivy Taia, Annika Hinze, Nicholas Vanderschantz \\ Computer Science Department, University of Waikato, Hamilton, New Zealand \\ imht1@students.waikato.ac.nz, \{hinze,vtwoz\}@waikato.ac.nz
}

\begin{abstract}
"He aha te mea nui o te ao, he tangata, he tangata, he tangata" "What is the most important thing in the world, it is people, it is people, it is people"
\end{abstract}

\begin{abstract}
Traumatic Brain Injury (TBI) is a world-wide "silent epidemic" causing a variety of memory issues for those affected. Although several software approaches aim to aid memory recollection, they are inadequate for many TBI survivors and none address aspects of cultural awareness in New Zealand. We explored design concepts of traditional Māori cultural tools $/$ techniques and how they helped Māori people recall past information. This paper describes our research and development of Maumahara Papahou, a mobile app that uses Augmented Reality features to create a digital memory treasure box based on the concepts of Māori mnemonic aids.
\end{abstract}

Mobile app, Traumatic Brain Injury, TBI, Augmented reality, Memory aid, Tikanga Māori

\section{INTRODUCTION}

Traumatic Brain Injury (TBI) is the leading cause of long-term disability of children and adult survivors, with an estimated 10 million people affected each year worldwide. It is expected that TBI will become the third largest global medical burden by 2020 (Feigin et al., 2013). Further, TBI is considered a worldwide "silent epidemic" (Rusnak, 2013) affecting the lives of the patients as well as their caregivers, families and friends.

In New Zealand, indigenous Māori people are disproportionately affected by TBI (Te Ao et al., 2014). Māori are at four times the risk of the general population, and they also face the risk of poorer outcomes (Barker-Collo, 2008). Studies have shown that different cultural practices, practitioner insensitivity towards cultural practice, socioeconomic status, communication issues and patients' personal experiences were contributing factors to poor treatment outcomes (Davis, 2006). Māori traditionally hold a more holistic view towards health and prefer to seek treatment within their extended family instead of seeking medical help in the hospital (Elder, 2013).

A number of technological aids are available for TBI survivors, such as voice recorders, games (Gilbert et al., 2017) and smartphone apps (Chang et al., 2018). For children and adolescents with memory impairment, smartphone technology is particularly well received (Plackett et al., 2017). There are still a number of gaps in the research into how to best support memory recollection for TBI survivors. Hinze et al. (2018) outlined the challenges encountered and lessons learned from developing augmented memory aids for people with TBI. We also observe that none of the existing works address aspects of cultural awareness in New Zealand.

We are committed to taking guidance from the Māori culture to identify suitable approaches to guide the development of memory aids (Hinze et al., 2018). This paper describes our first foray into transferring concepts from Māori mnemonic aids into mobile memory aids for TBI survivors. Here we describe our explorations of design concepts of traditional Māori cultural tools and techniques that were used to help of recall past information, especially in oral story and history telling.

This paper describes the development of a mobile app that uses Augmented Reality (AR) features to create a digital memory treasure box based on the concepts of Māori mnemonic aids. We have called this app Maumahara Papahou, which is translated as Maumahara: to remember and Papahou; treasure box.

\section{MĀORI MNEMONIC AIDS}

We explored a diverse range of Māori mnemonic tools and techniques that helped in the retention, recall and sustainability of the Māori culture. From this exploration, design concepts and theories were 
considered for the development of our augmentedreality app for TBI survivors.

For generations, Māori people used mnemonic aids to recall past information, such as purakau (myths and legends), wāhi whenua, pou pupuru whenua me ingoa wāhi (landscapes, landmarks and place names), taonga ki te pātaka (objects as storehouses), whakapapa (genealogies), rākau whakapapa (orator's mnemonic staff), whakairo (Māori carvings), ngā waiata, haka me mōteatea (songs, war dances and Māori chants), tā moko (traditional Māori tattoo), tukutuku me tāniko (latticework and embroidery), whāriki me raranga (woven mats and food baskets), tekoteko, poupou me wakahuia (carvings of human figures, carved panels and treasure boxes).

Objects are great examples of storehouses for cultural memory and practice. Māori people regard objects as taonga (see Figure 1), especially those that hold a significance such as being passed down from tūpuna or ancestors (Lyons \& Marshall, 2014). A typical taonga that is being passed on is a piece of greenstone or bone jewellery that may have been carved or engraved using traditional visual symbology. They are reminders of the connections one has with people passed on and allow a person to forward that knowledge on to someone else when one is ready to leave this world, giving the object additional meaning.

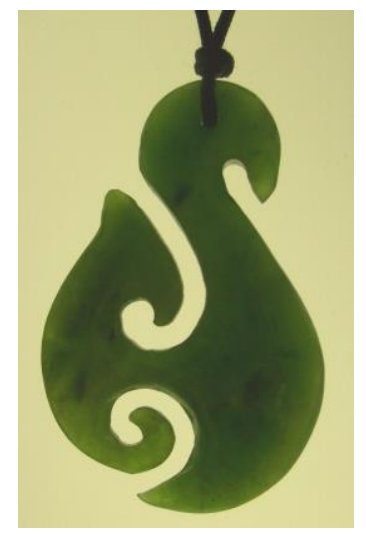

Figure 1: Pounamu (Greenstone) Taonga

Traditional Māori orators use a rākau whakapapa (orator's mnemonic staff) with protruding notches to help them memorise tribal lineage (Taonui, 2011). The orator would move their fingers over the protruding notches reciting different genealogy at each new notch.

The Maori Mnemonic Aids that we have chosen to focus our investigations on are the wakahuia and the papahou. The papahou (Figure 2) and wakahuia (Figure 3) are two types of carved wooden containers that hold personal treasures such as amulets, pendants, combs and feathers. Papahou and wakahuia are similar in design; wakahuia are mostly oval shaped containers while the papahou is an oblong or rectangular shaped container. Sizes range between 30 to 60 centimetres in length. The current application was based on a papahou design. A wakahuia usually contained a feather from the "Huia" bird, hence the name wakahuia. Commonly known as "Māori treasure boxes" they were elaborately carved. Some were made with handles, some with bases and others, without. Traditional wakahuia were given names and became valued taonga and were hung from the ceiling so to admire the underside (Revolvy, 2018).

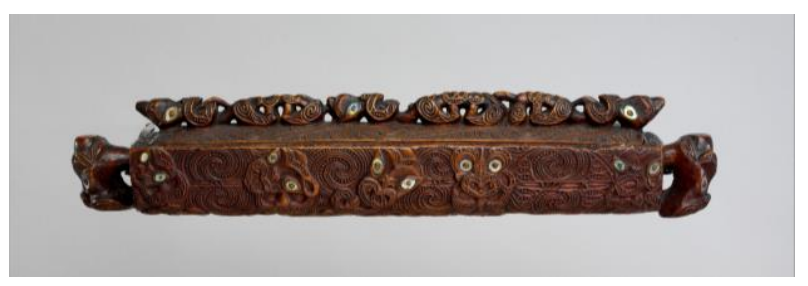

Figure 2: Papahou

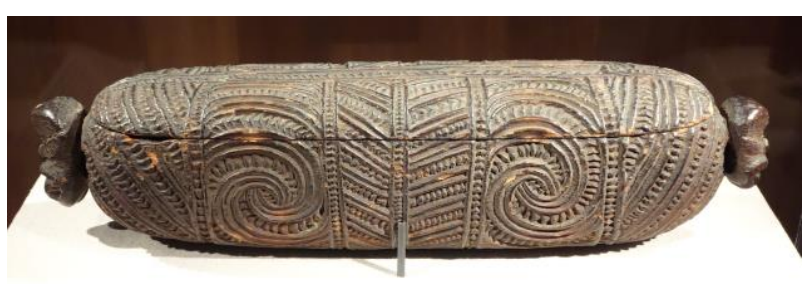

Figure 3: Wakahuia

\section{AR APP DESIGN PROCESS}

To address the problem of how to implement Māori mnemonic aids in a mobile app to support TBI patients we first identified two specific user groups: TBI survivors (main users), who had sustained a brain injury and their supporters (secondary users), the people who would use the application in support of the main user-who is likely their patient or family member. The needs of the main user have been the central focus of the design and development of this mobile app. We defined a main user as someone who would score between 9 and 15 on the Glasgow Coma Scale (Feigin et al., 2013). This user would be considered a person who suffers 'moderate' or 'mild' effects of TBI. The design of our app was guided by design concepts from traditional Māori mnemonic tools. We developed usage scenarios and focussed on implementing core functions of an app: viewing memory objects, and viewing, updating and saving the memory information.

The design solution we identified through this process is the Maumahara Papahou application that provides a 3D Augmented Reality experience for TBI survivors and their supporters. Our app specifically reimagines the papahou as a digital treasure box in 3D AR app form and allows the user to virtually see and touch treasure (taonga) that represent their memories. Figure 4 shows one of the conceptual drawings and also the finished AR design. 
We designed the concepts and implemented visual interpretations of traditional objects associated with memory in Māori culture (Figure 5). These included a rei puta or whale tooth pendant (designed by "Cults3D", 2017) and koauau or flute (designed by SketchFab, 2017) and a Māori carving design that adorns the sides and lid of the papahou (designed by Koru Korua Tae, 2017). The 3D memory objects serve as devices within the treasure box that we can use to associate with recorded memories.
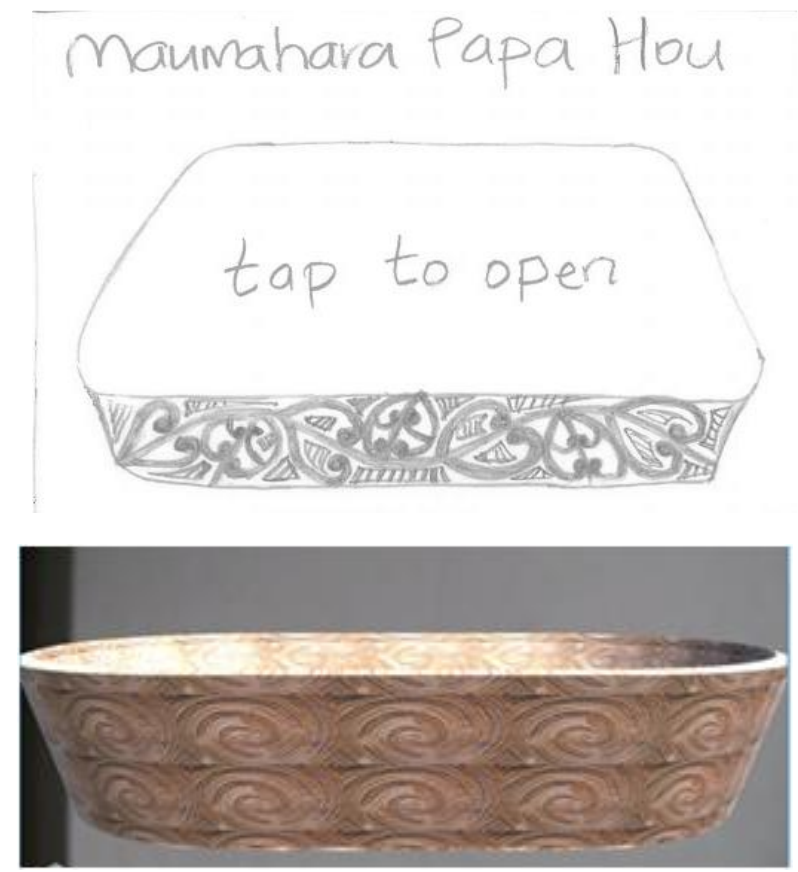

Figure 4: concept drawing (top) and implementation (bottom) of Maumahara Papahou 3D Treasure Box
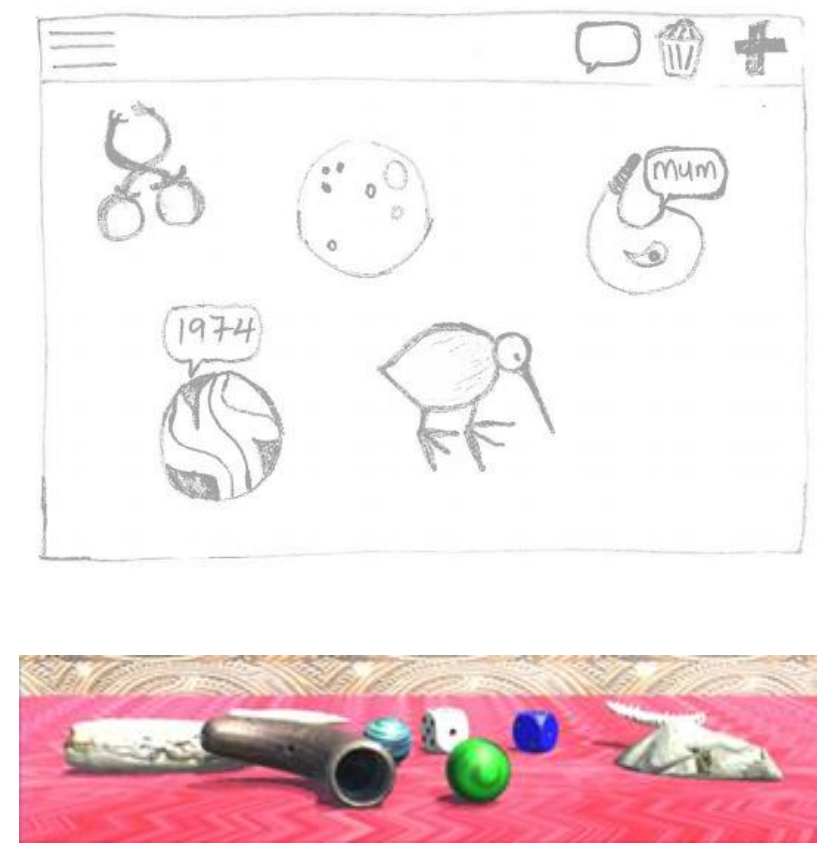

Figure 5: Traditional Māori objects - conceptual design (top) and implementation (bottom)

\section{APP WALK THROUGH}

The app is started by selecting the app icon on a tablet's app collection. The start screen of the app appears, showing a carved treasure box with a slowly rotating lid (see Figure 6).

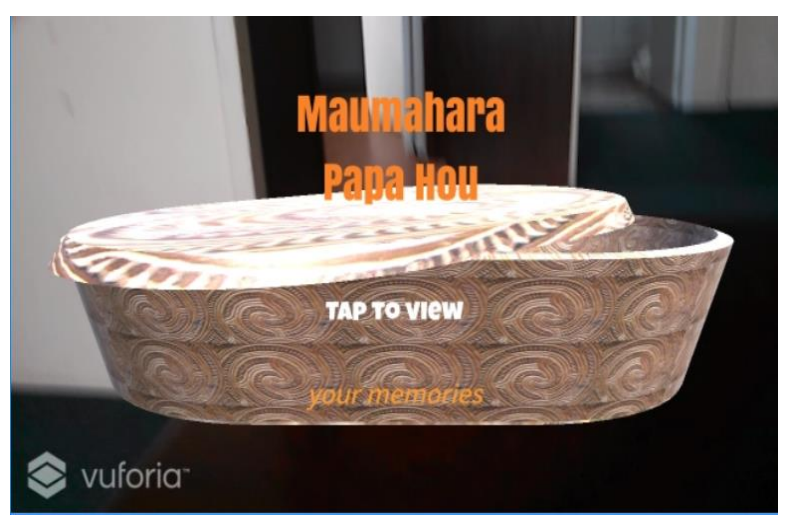

Figure 6: Start AR view of turning papahou

The user taps the object to start the interaction with the box and the camera zooms into the treasure box and the memory objects come into view. The objects can be moved within the box. To explore an object's connected memories, the user may tap the wooden flute (see Figure 7).

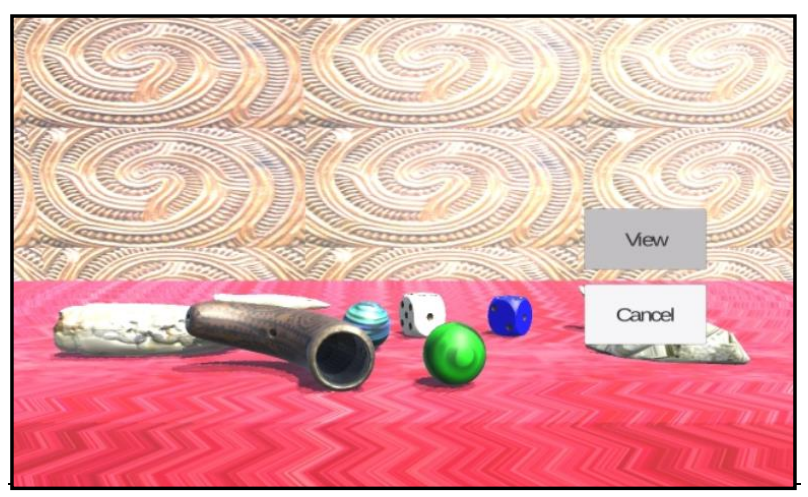

Figure 7: Selecting an object to view memory details

After selecting to view the memory details, a screen appears with simple information about the memory, designed to trigger remembering.

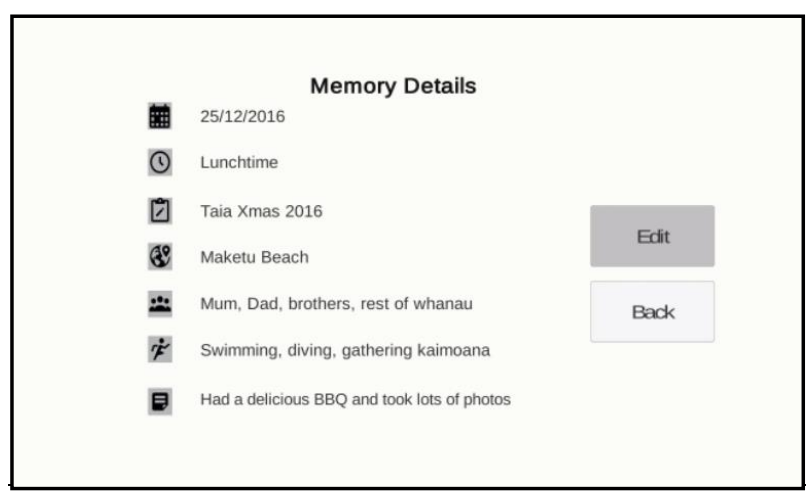

Figure 8: Memory details of an object 
For more detail about suitable memory cues, see (Chang et al., 2018). The user may update the memory details (see Figure 9), or merely look at these for memory training (see Figure 8).

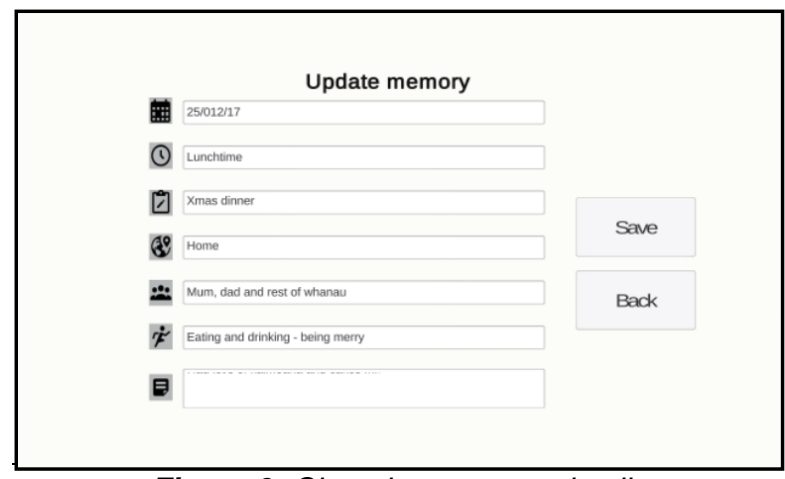

Figure 9: Changing memory details

Users with TBI and their families or caregivers may look at the memory objects together, exploring their content in order to support recall.

\section{DISCUSSION}

We discuss here briefly our design decisions and overall project consideration that shaped the app development process.

Culturally aware health interventions. Our work is based on the work of Elder (2013), who argues that Maori health is a community-based health concept. She developed a paper-based approach to supporting TBI survivors that engaged the whole whanau (wider family). Elder recommends taking guidance from Māori culture to best understand the needs of the individual in the context of their community, which has been a central focus of the app development described here.

AR on mobile end-user devices. The decision for using AR technology was based on the lack of immersive rehabilitation support systems for TBI survivors that would be available for people in their every-day environments. The reason for using a $2 D$ based interface for data entry and editing was based on the research of the MyMemory application (Chang et al., 2018). They developed a 2D text entry "icon-based" interface for their MyMemory app, which we rely on for memory information ingest into our application. We follow them in their argument that that TBI survivors prefer a simple design with 'enough' functions (vs an overly complex interface or too sophisticated functions potentially leading to cognitive overload).

Maori and app development. The extent of currently available apps specifically for or about Maori and Maori culture is limited. Most available apps focus on teaching Te Reo Maori (the Maori language) or Maori customs (Tikanga Maori) and Maori cultural beliefs. A few apps are about restoring
Maori sovereignty and showcasing projects on their native land.

\section{CONCLUSION \& FUTURE WORK}

Our project aimed to develop a health intervention that supports TBI survivors using an immersive mixed reality interface on commonly available mobile technologies. We incorporated concepts of traditional Māori cultural tools and techniques that have helped Māori people retain and recall past information in an oral culture.

We identified a range of different traditional aids that Māori people used to help them remember past information. The design concepts and techniques used in developing those aids were vast and not all were considered for the development of the current application. We chose the treasure box metaphor of the papahou (memory box) to implement as an AR interface for our app. This memory box concept will be familiar to Māori users and is an artefact that will also translate to nonMāori users who will also be familiar with treasure boxes in their own cultures.

This paper has described the design process undertaken to develop the Maumahara Papahou app. We discussed the design and interaction considerations we explored to develop a mobile system that is appropriate for TBI survivors and their supporters, especially for recall of memories and reminiscence. We showcased the Maumahara Papahou application in a walk-though.

Our future work sees the Maumahara Papahou application being tested in a longitudinal study with Māori and non-Māori TBI survivors and their supporters. In this upcoming study we will be investigating the user interactions with the app as well as the perceived successes in recording and associating memories with AR artefacts. Further developments of the app based on the insights from the expert review will be undertaken, such as the extension of the use of colour in the app and further enhancement of the user interface. We also wish to enhance the use of traditional Māori taonga in this immersive AR environment, e.g., through incorporation of further relevant objects.

\section{REFERENCES}

Chang, S. C., Hinze, A., Bowen, J., \& Starkey, N. J. (2018). "MyMemory: A Mobile Memory Assistant for People with Traumatic Brain Injury", Int. Journal of Human-Computer Studies, Springer, doi.org/10.1016/j.jhcs.2018.02.006

Cults3D. (2017). Rei puta - Māori pendant. Retrieved from https://cults3d.com/en/3dmodel/art/rei-puta-Māori-pendant 
Davis, P., Lay-Yee, R., Dyall, L., et al. (2006). Quality of hospi-tal care for Māori patients in New Zealand: retrospective cross-sectional assessment. The Lancet, 367(9526), 1920-1925.

Elder, H. (2013). Te Waka Oranga: An indigenous intervention for working with Māori children and adolescents with traumatic brain injury. Brain Impairment, 14(3), 415-424.

Feigin, V. L., Theadom, A., Barker-Collo, S., Starkey, N. J., McPherson, K., Kahan, M., \& Jones, K. (2013). Incidence of traumatic brain injury in New Zealand: a population-based study. The Lancet Neurology, 12(1), 53-64.

Gilbert, L., Hinze, A., \& Bowen. J. (2017). Augmented Reality Game for People with Traumatic Brain Injury: Concept and Prototypical Exploration. In Proceedings of the 9th International Conference on Computer and Automation Engineering (ICCAE '17). ACM, New York, NY, USA, 51-55.

Hinze, A., C. Timpany, J. Bowen, C. Chang, N. Starkey and H. Elder (2018) Digital support for people with Traumatic Brain Injury: Exploring sensitive and personal data, 2018 British $\mathrm{HCl}$ conference, Belfast, UK

Koru Korua Tae. (2017). Koru Carving. Retrieved from https://www.korukoruatae.com/taongaphoto-gallery.html

Lyons, N., \& Marshall, Y. (2014). Memory, practice, telling community. Canadian Journal of Archaeology, 38(2), 496-518.
Plackett, R., Thomas, S., \& Thomas, S. (2017). Professionals' views on the use of smartphone technology to support children and adolescents with memory impairment due to acquired brain injury. Disability and Rehabilitation: Assistive Technology, 12(3), 236-243.

Revolvy. (2018). Waka huia. Retrieved from https://www.revolvy.com/main/index.php?s=Wak a\%20huia

Rusnak, M. (2013). Traumatic Brain Injury: Giving voice to a silent epidemic. Nature Reviews Neurology $\quad 9$, 186-187. doi:10.1038/nneurol.2013.38.

Sketchfab. (2017). Gourd Māori Nguru (Nose Flute). Retrieved from https://sketchfab.com/models/79152b81cd18443 1abd1c77f3296870d

Taonui, R. (2011). 'Whakapapa - genealogy Recalling whakapapa'. Te Ara - the Encyclopedia of New Zealand. from www.teara.govt.nz/en/object/30918/rakauwhakapapa

Te Ao, B., Brown, P., Tobias, M., Ameratunga, S., Barker-Collo, S., Theadom, A., McPherson, K., Starkey, N., Dowell, A., Jones, K. and Feigin, V.L. (2014). Cost of traumatic brain injury in New Zealand evidence from a population-based study Neurology, 83 (18), pp. 1645-1652

Tuarangi. (2018). Tekoteko Māori Carved Human Figures. Retrieved from http://www.tuarangi.com/tekoteko-Māori human-carved-figures/ 